\title{
Actuation, monitoring and closed-loop control of sewing machine presser foot
}

\author{
Luís F. Silva', Mário Lima ${ }^{1}$, Helder Carvalho², \\ Ana M. Rocha², Fernando N. Ferreira ${ }^{2}$, \\ João L. Monteiro ${ }^{3}$, Carlos Couto ${ }^{3}$
}

${ }^{1}$ Department of Mechanical Engineering, ${ }^{2}$ Department of Textile Engineering, ${ }^{3}$ Department of Industrial Electronics, School of Engineering, University of Minho, 4800-058 Guimarães, Portugal

\begin{abstract}
Sewing is one of the most important processes in the apparel industry for the production of high-quality garments. Although some research and improvements have been carried out in this area, the sewing process has remained almost unchanged throughout the years, staying largely dependent on the operator skills to set up sewing parameters and to handle the fabrics being sewn. Slight changes in sewing machine settings can influence the quality of seams, as well as sewing operation time. To avoid these empirical settings, reduce set-up times and improve machine performance, flexibility and sewing quality, an electromagnetic actuated presser foot, based on the use of a proportional force solenoid, was developed and implemented on an industrial overlock sewing machine. The compression force and displacement waveforms from the presser foot bar will be studied in this paper, as well as the admissible displacement limits used to monitor (on- and offline) fabrics' feeding efficiency. Following this analysis, a new research programme was established to enable a PC-based open- and closed-loop control of the presser foot system. This paper also highlights these recent developments, presenting and discussing, in detail, a PID closed-loop control strategy. The obtained results show that the presser foot closed-loop control has improved performance for a wide speed variation range.
\end{abstract}

Key words: electromagnetic actuated presser foot; feeding efficiency monitoring; overlock sewing machine; presser foot closed-loop control; presser foot system.

Address for correspondence: Luís F. Silva, Department of Mechanical Engineering, School of Engineering, University of Minho, 4800-058 Guimarães, Portugal. E-mail: lffsilva@dem.uminho.pt 


\section{Introduction}

Since the early 1990s, the sewing process (namely needle penetration, stitch formation and fabric feeding dynamics) has been studied at the University of Minho gathering different background researchers at the Laboratory of Process Research. A 'sewability' tester based on an industrial overlock sewing machine, firstly developed by Rocha et al. (1996), redesigned and improved over the years by Carvalho and Ferreira (2000), Carvalho et al. (1998, 2000) and Silva et al. (2000a, b), is now able to measure simultaneously the presser foot bar compression force and displacement, the force on the needle bar and the needle and loopers' thread consumption and tension, using:

1) two piezoelectric force transducers, on the presser foot and needle bars,

2) one displacement transducer (LVDT), on the presser foot bar,

3) three encoders, on the thread paths, and

4) three semiconductor strain gauge transducers, also on the thread paths, close to the needle and (the upper and lower) loopers.

This 'sewability' tester was used to assess the performance of the sewing machine's feeding system (made up of a standard presser foot, with an helical compression spring on its bar, a throat plate and a differential feed dog) and led to a better understanding of the system dynamics. In all studied cases, reported elsewhere by Silva et al. (2000a, b), the presser foot bar compression force waveforms have shown, during the feeding period, wide variations with increasing machine speed. Immediately after the feed dog has been lowered beneath the throat plate level, a final peak in the force waveforms also indicates the instant when the presser foot re-establishes contact with the fabrics against the throat plate, showing again other force variations. These variations suggested that the spring actuation was not adequate to guarantee an appropriate and constant contact between the presser foot and fabric plies. Because to this, two contact losses occurred during each cycle when the compression forces showed a tendency to decrease. The first contact loss happened during the feeding period, at the topmost position of the feed dog above the throat plate level, and, the second, soon after the feed dog has been lowered beneath that same level, after feeding.

Therefore, precise and accurate control of the fabric plies proved essential to reduce, or even eliminate, the loss of feeding efficiency that positively reduces the quality of the produced seams.

\section{Electromagnetic actuated presser foot}

To avoid this presser foot 'adverse' dynamics, a decision was taken to redesign the fabric feeding system and a proportional force solenoid was found to be the most suitable for this application. Figure 1 shows the developed presser foot actuation set-up, with the actuator attached sideways to the presser foot bar, without modifying the arrangement of the piezoelectric force and LVDT transducers included in the previous phase for studying the performance of the standard presser foot system. 
Figure 1 Transducers arrangement and presser foot actuation set-up, with the proportional force solenoid placed sideways to the presser bar

This actuation set-up was tested on an identical overlock sewing machine and using a second 'sewability' tester, built for this purpose, with optimized signal conditioning boards for the measuring system and a dedicated driver for the actuation. The proportional force solenoid has been used in a 'continuous' mode, providing a force proportional to the current and independent of the displacement in the used range. The current needed to drive the solenoid, to apply the total force to the presser foot bar, was correlated with the sewing conditions, namely with the wide force variations observed for all tested fabrics (jersey, rib $1 \times 1$ and interlock).

The acquired presser foot bar compression force and displacement waveforms showed that the contact losses observed while testing the standard presser foot system, as mentioned in the previous section, have completely disappeared and the fabric plies were now under control, not only in the feeding period but also after the feed dog has been lowered beneath the throat plate level. These observations were consistent throughout the experiments for all tested fabrics and at different sewing speeds.

These conclusions were also confirmed by evaluating the quality of the produced seams. As is commonly accepted, after proper machine adjustments, an efficient feeding system should be able to guarantee the same stitch density, inde- 
pendent of the fabrics or speeds involved. Ideally, the obtained stitch density should always match that defined with nominal machine settings. As an example (Silva et al., 2000b, 2002 present more detailed information about this analysis), Table 1 summarizes the average number of stitches per $\mathrm{cm}(\mathrm{spcm})$ counted over several 5-cm seam lengths for three different speeds (2000, 3000 and 4700 stitches per minute, spm) and for all jersey samples tested. It must also be noticed that the needle and the sewing threads were chosen as the most adequate to sew these knitted fabrics and the thread tensions were properly adjusted to obtain a plain and balanced seam.

Using the helical spring on the presser foot bar, the difference between the actual stitch density and the nominal one increases with machine speed. For the jersey fabric (Table 1), this loss of efficiency can be explained by the contact losses observed between the presser foot and the fabrics. Due to this 'bounce', the presser foot is unable to control the fabrics and the stitch length tends to increase with machine speed, decreasing, therefore, the stitch density.

On the other hand, these differences have decreased using the proposed actuation set-up, with or without the helical spring on the presser foot bar. Again for the jersey fabric (Table 1), it can be observed that there is a tendency, in both cases, to improve the control of fabric feed. However, in average terms, the minimum variation in stitch density was found using just the solenoid for all speeds tested.

For all fabrics, the stitch densities obtained by varying the drive currents showed that a decrease in the force applied to the presser foot bar led to an increase of the density differences. These differences showed the same trend for each fabric using the standard presser foot; however, they were much smaller. These results show that a controlled movement of the fabric plies, to guarantee a correct stitch formation, has been achieved with the modified presser foot actuation system.

Figure 2 displays a close-up view of some rib $1 \times 1$ and interlock samples sewn at 2000 and $4700 \mathrm{spm}$ using the proposed presser foot actuation system. These

Table 1 Nominal and actual stitch densities obtained with two plies of a jersey fabric

\begin{tabular}{lcccc}
\hline System type & $\begin{array}{c}\text { Machine speed } \\
(\text { spm })\end{array}$ & $\begin{array}{c}\text { Nominal stitch } \\
\text { density } \\
(\text { spcm })\end{array}$ & $\begin{array}{c}\text { Actual stitch } \\
\text { density } \\
(\text { spcm })\end{array}$ & $\begin{array}{c}\text { Variation } \\
(\%)\end{array}$ \\
\hline Helical spring & 2000 & & 3.80 & -5.0 \\
& 3000 & 4 & 3.75 & -6.25 \\
Solenoid and spring & 4700 & & 3.65 & -8.75 \\
& 2000 & & 3.85 & -3.75 \\
Solenoid & 3000 & 4 & 3.95 & -1.25 \\
& 4700 & & 4.03 & +0.75 \\
& 2000 & & 3.98 & -0.5 \\
& 3000 & 4 & 4.03 & +0.75 \\
& 4700 & & 4.05 & +1.25 \\
\hline
\end{tabular}


seams were obtained with the proportional force solenoid applying all the force to the presser foot bar to secure the plies during sewing. The seams produced were extremely regular and without any kind of defects that could be attributed to the feeding system.

\section{Monitoring the feeding efficiency}

The principles for the development of a suitable feeding efficiency monitoring system (used, successfully, on- and offline) has already been reported more extensively by Silva (2002). This method, named admissible displacement limits (ADL), came after another approach based on spectral analysis in order to characterize feeding performance and to obtain other relevant features of the signals acquired by the transducers.

According to the control values, ADL establishes the upper and lower presser foot bar admissible displacement limits over which it is still possible to obtain good-quality seams, as a function of the imposed seam quality. If any value is plotted outside the admissible area, a warning display alerts the operator that the quality of the produced seam will not be the expected one. 
Figure 3 shows the main configuration panel of the 'sewability' tester for feeding assessment. This software was developed (by Carvalho et al., 1998, 2000) using the LabView graphical programming language with specific routines to assess process behaviour. (In this figure, some of the presented displacement waveforms show the tendency that occurs with the decrease of the force applied by the proportional force solenoid to the presser foot, while sewing two plies of the jersey fabric and keeping the speed constant at $4700 \mathrm{spm}$.)

After selecting the displacement waveforms to analyse, and establishing the type of 'sewability test' to perform, this panel enables the definition of the stitch cycle phases for computing its maximum displacements (Figure 3). The two defined phases for all the displacement waveforms shown in this panel correspond to the two 'critical' points observed in all studied cases using the standard presser foot with the helical compression spring. The first (maximum displacement) occurs during the feeding period, at the topmost position of the feed dog above the throat plate level, and, the second (second displacement), shortly after feeding, as mentioned previously.

Figure 4 highlights some monitoring results using the ADL method. These tests were computed considering the upper and lower (admissible) displacement limits that correspond to a stitch density variation of $0 \%$ (determined as the difference

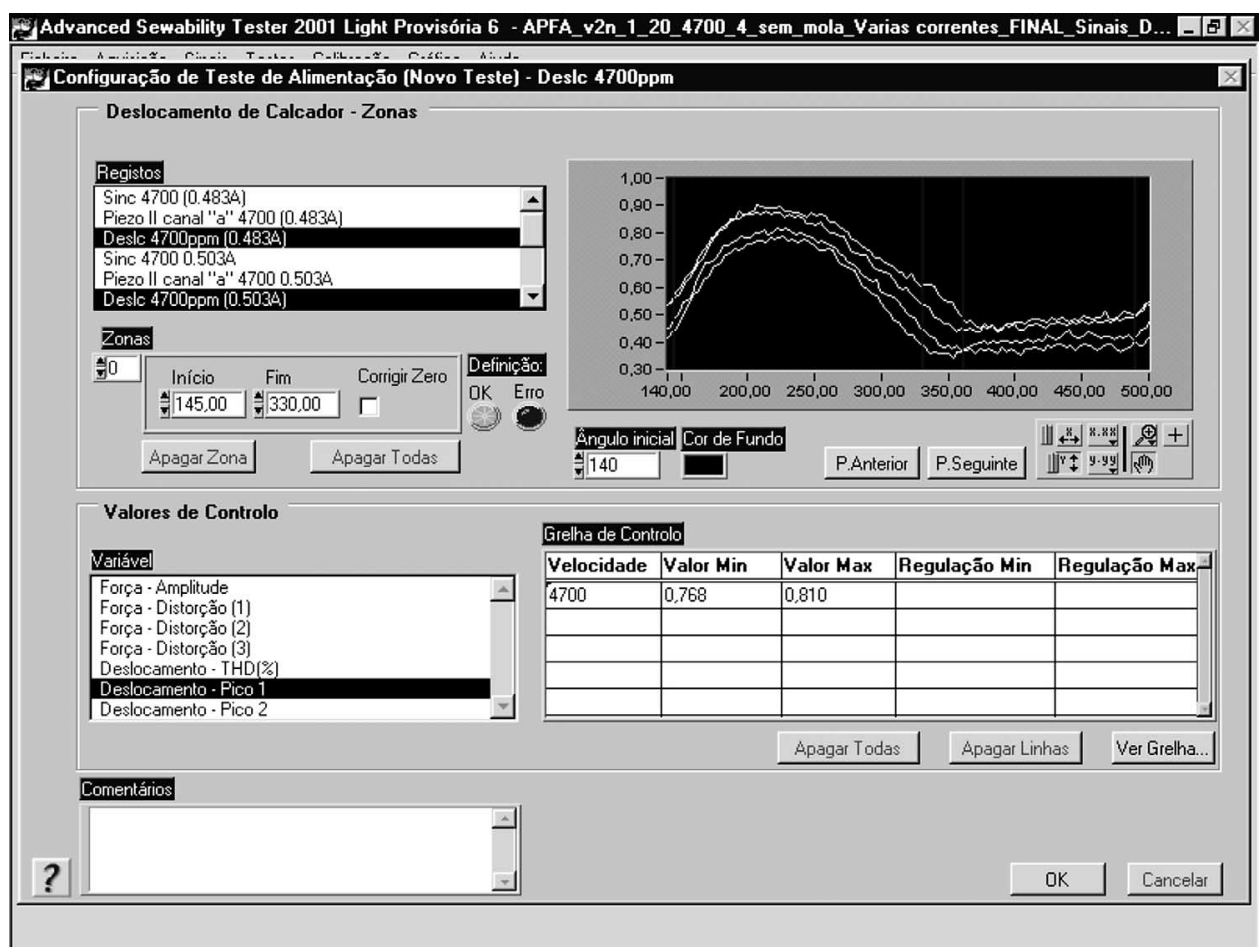

Figure 3 Configuration panel of the 'sewability' tester for feeding assessment (showing four presser foot displacement waveforms, two defined - displacement - phases and the control grid) 


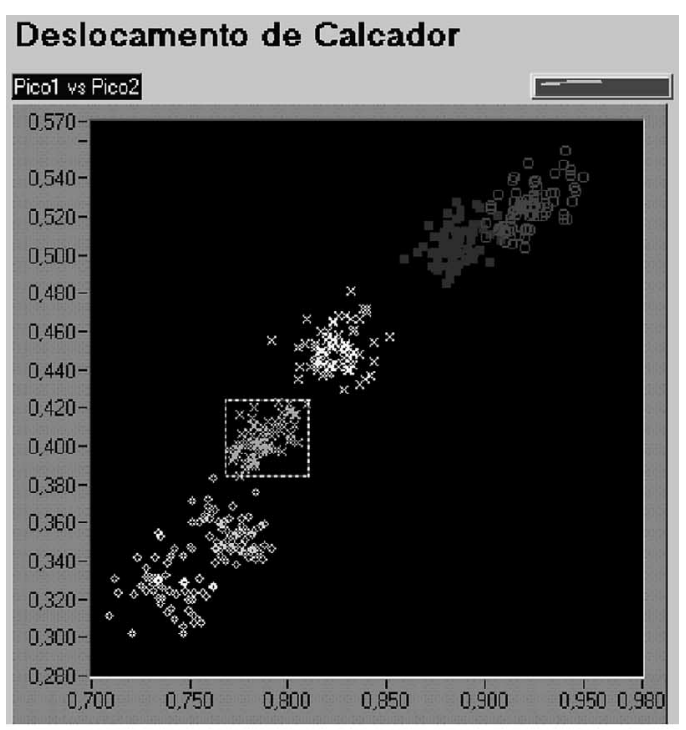

Deslocamento Calcador-Sequência cronológica

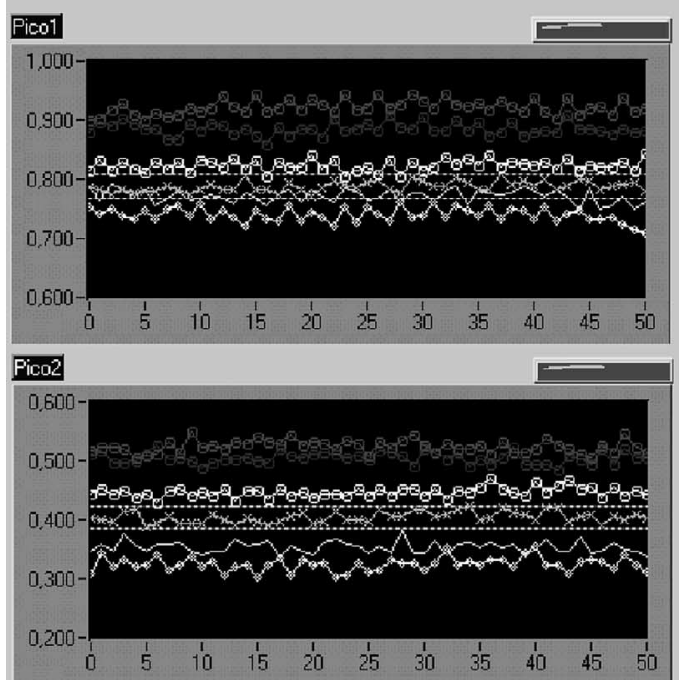

between the actual and the nominal stitch density). The first graph plots the maximum displacements for both 'critical' points, while the second and third graphs display the chronological sample sequence also for both 'critical' points (maximum and second displacements). The dashed lines on each graphical rep-

Figure 4 The ADL (admissible displacement limits) method: monitoring and chronological displacement sequence. Upper graph: horizontal axis, maximum displacement; vertical axis, second displacement, after feeding. Second and third graphs: horizontal axis, stitch cycles; vertical axis, maximum and second displacements, respectively. 
resentation define the corresponding admissible displacement limits established by the control values (Figure 3), according to the imposed density variation of $0 \%$. The alert display on the right upper hand side on these three graphs turned red, since some displacement coordinates were plotted outside the admissible area.

All these results are described in more detail elsewhere by Silva (2002) and the ADL method was used as a first step towards automatic control. Therefore, and after this stage, research efforts were directed to the design of two PC-based presser foot control schemes, presented and discussed over the next topics.

\section{Implemented control strategies}

In order to improve even more sewing machine flexibility, it was decided to study possible control schemes that could be suitable for this application.

To reach this objective, this study began with the development of a software driver, in LabView, for the application of a constant force to the presser foot bar. Instead of manually adjusting the forces using a potentiometer available on the actuator drive-circuit, this PC driver eases force setting according to user/technician need to sew a certain type of fabric.

\subsection{Open-loop control}

One interesting finding while testing the redesigned presser foot actuation set-up (with the proportional force solenoid attached sideways) is that there is an admissible force range to obtain good-quality seams. The control curves (that plot the relationship between the force applied by the solenoid to the presser foot bar and the sewing speed) were determined for all tested knitted fabrics considering a stitch density variation of $\pm 1 \%$. These force ranges are related to a certain range of admissible displacement limits that are monitored by the ADL method previously presented.

Therefore, the PC-based open-loop control was established according to these control curves, as a function of the imposed seam quality, knowing that the force applied by the electromagnetic actuator should be proportional to the measured sewing speed: one straight line per fabric best fitting the respective control curves measured.

After computing the sewing speed, using a specifically designed routine, the force intended to provide a controlled movement of the fabric plies is converted into an electric output by the controller to drive the proportional force solenoid.

The presser foot bar displacement waveforms obtained during experiments showed, as expected, no contact losses between the presser foot itself and the fabrics running at constant speed when stitching two plies of $1 \times 1$ rib fabric (the type of fabric used in these experiments). During quick speed transitions, from lower to higher speeds, the presser foot bar displacements tend to increase. Nevertheless, the displacements reach the same top values observed at constant speed 


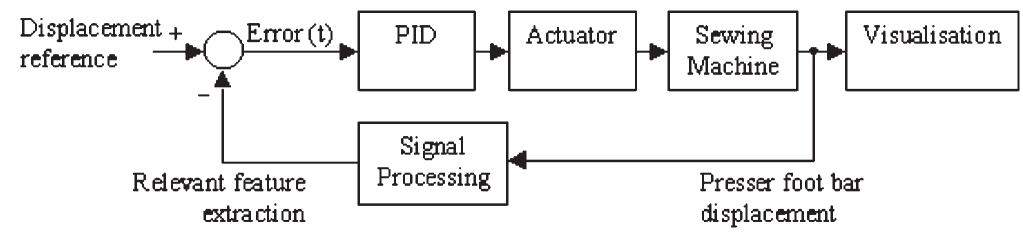

Figure 5 Closed-loop control block diagram

shortly after this transition period (that relates to the dynamic response of the actuator).

Although the sewing speed has been used as the control variable for this approach, it does not (directly) describe fabric feeding efficiency. Therefore, the next approach was to develop and implement a closed-loop control strategy, with feedback variables capable of defining the process state directly, to guarantee better performance.

\subsection{Closed-loop control}

A closed-loop control was developed computing the presser foot bar maximum displacement peak, above the throat plate level, as the feedback variable to be compared with a reference defined within the admissible displacement references measured that guarantee good feeding performance (and seam quality) under any circumstances.

This closed-loop control strategy was designed according to the block diagram schematically displayed in Figure 5.

4.2.1 The controller: This PC-based closed-loop using a PID controller, programmed in LabView, with specific routines to acquire, process, actuate, display and analyse all the information (waveforms and numerical parameters), was implemented to assess feeding behaviour and its performance.

The operation principle of the signal processing stage, for extracting relevant features of the presser foot displacement waveforms, is depicted in Figure 6.

After acquisition, the displacement waveform is processed to compute its maximum peaks (and the correspondent stitch cycle angles) enabling process actuation through the PID. The definition of the stitch cycle angles is obtained using the 'synchronization signal'. This signal, coming from the machine motor, delivers a pulse at a specific point of the stitch cycle. It is fed into the data-acquisition board to trigger acquisitions, to provide data to measure sewing speed and to define an angle scale for the signals based on the stitch cycle. The control parameters were determined and initialized to those obtained using the Ziegler-

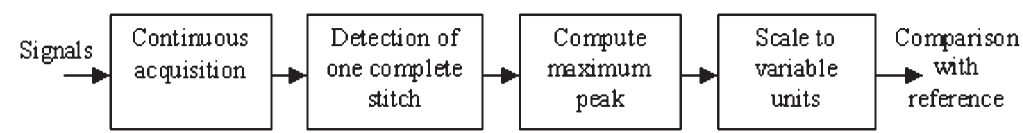

Figure 6 Closed-loop control of presser foot peak displacement 
Nichols criteria (National Instruments, 2001), after making the presser foot system (including the fabric plies) to oscillate.

Figure 7 shows the front panel of the developed closed-loop control program, displaying the performance of the control algorithm at an initial stage of development. The reference was set to $1.0 \mathrm{~mm}$, and the graph shows the presser foot bar displacement and the control signal applied to the actuator.

4.2.2 Results and discussion: The following figures (Figures 8-10) display the first set of waveforms obtained with the developed PID controller while sewing two plies of the rib $1 \times 1$ fabric. The succession of all figures highlights the performance of the presser foot bar displacement; quickly varying sewing speeds from $4700 \mathrm{spm}$ to a minimum of $2000 \mathrm{spm}$, with the PID displacement reference set to $0.9 \mathrm{~mm}$.

All maximum displacements computed offline in a stitch-to-stitch analysis, above the throat plate level, was shown to be consistently $0.9 \mathrm{~mm}$, within a tolerance of $\pm 0.05 \mathrm{~mm}$. This presser foot bar displacement variation is perfectly inside the admissible limits determined earlier for this knitted fabric to obtain goodquality seams (in terms of stitch regularity).

The presser foot appears to be under control during all tested speed variations (from high-to-low and also from low-to-high speeds, being the latest variation the most 'critical' operative mode). The visual inspection of all samples revealed that

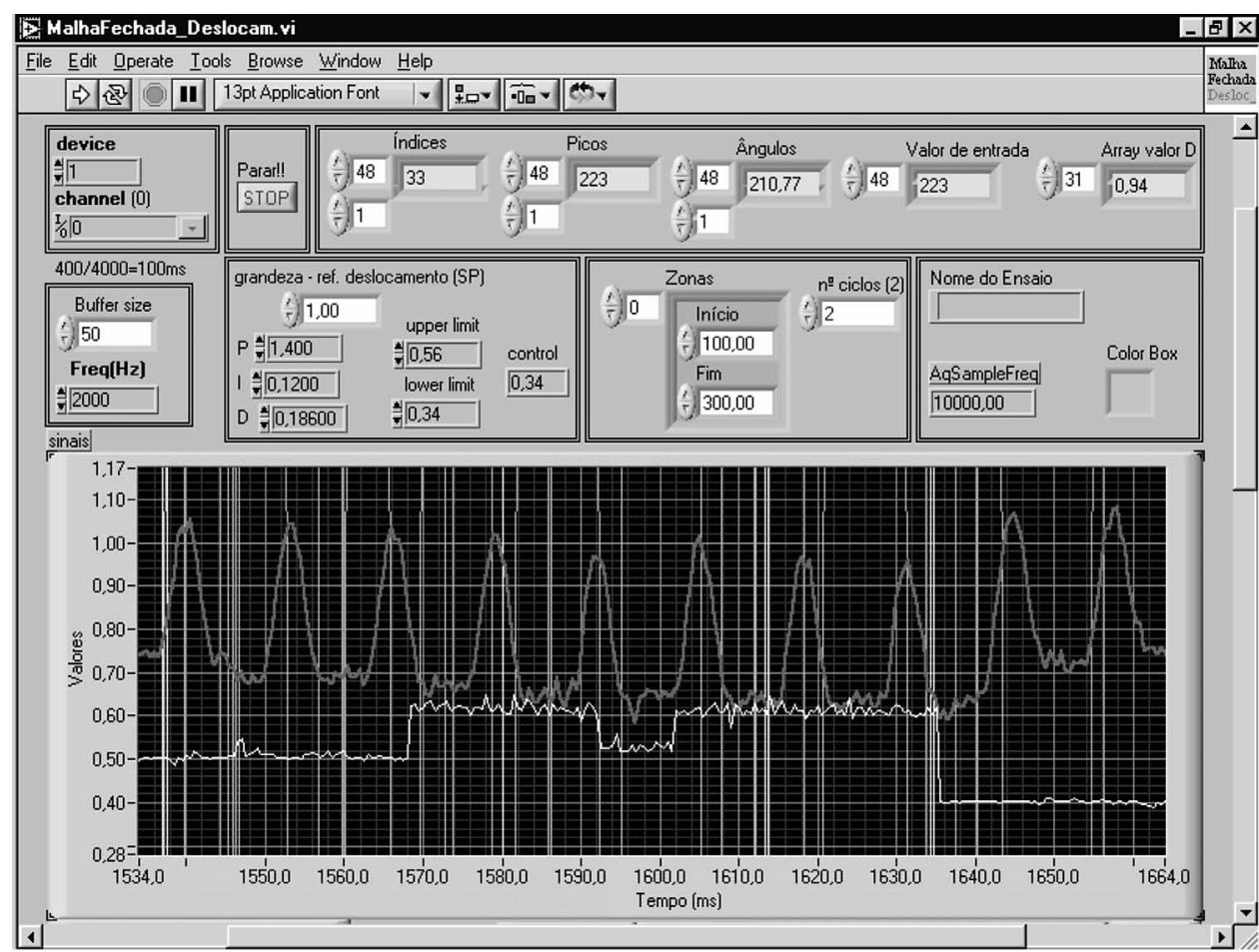

Figure 7 Front panel of the PC-based closed-loop control 


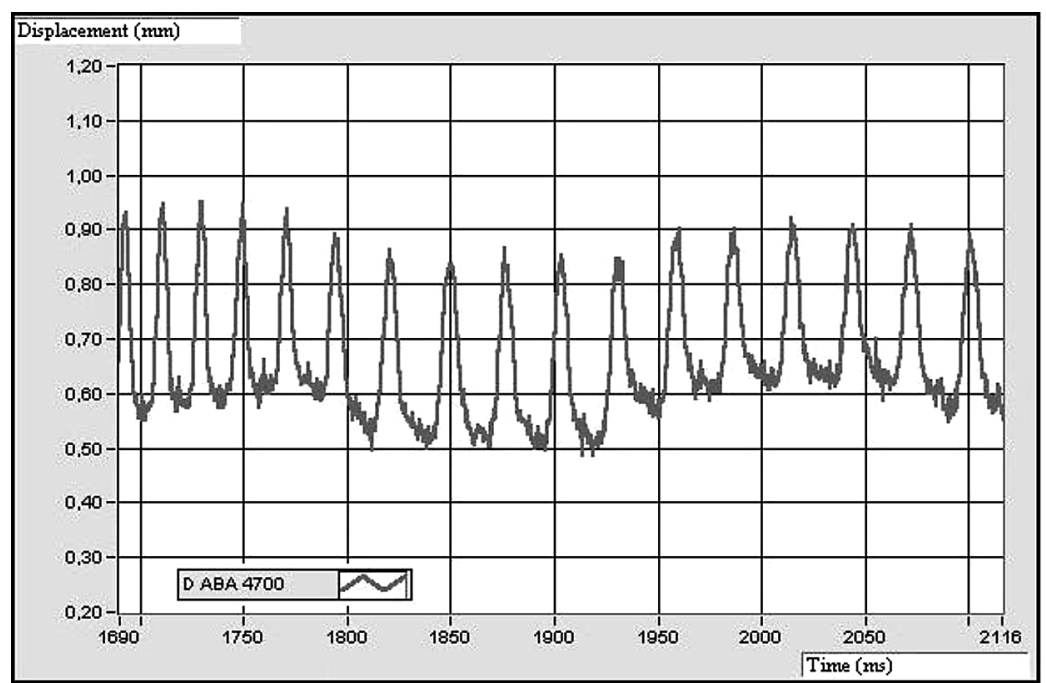

Figure 8 Displacement waveforms obtained from high-to-low speed transitions

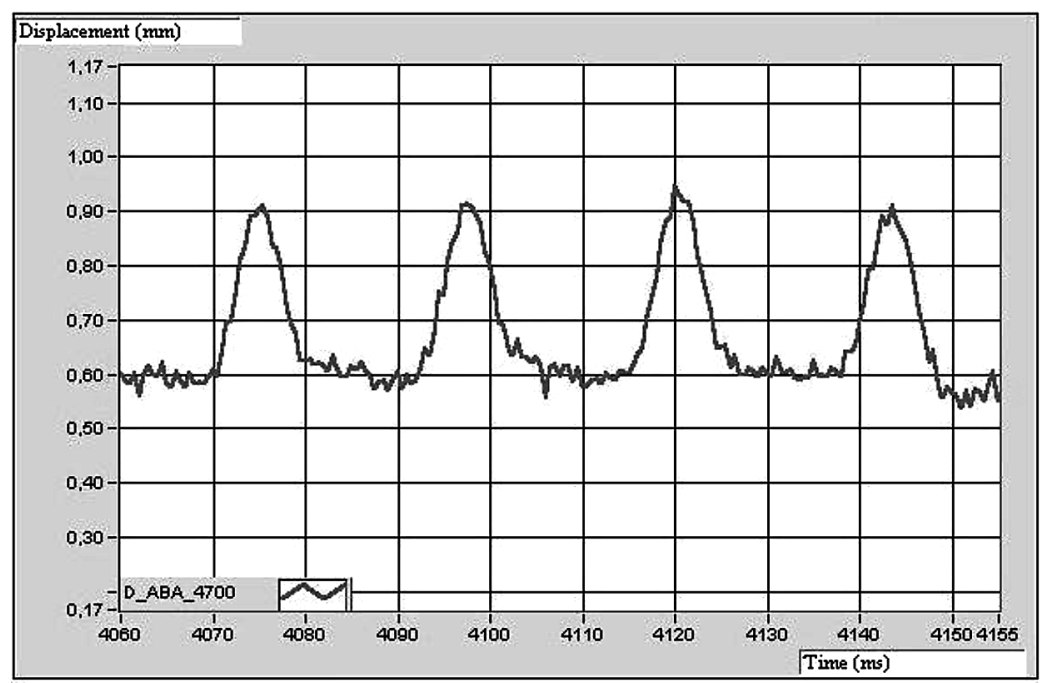

Figure 9 Displacement waveforms obtained at lower, constant speed

the produced seams are regular, without any defects that could be addressed to the feeding system, and within an expected stitch density variation of $\pm 1 \%$.

According to our best knowledge and common agreement, it is possible to improve this closed-loop control even further. A more precise fine-tuning of the PID gains and force ranges involved, to sew this type of fabric, will probably increase the performance and reliability of the proposed PID PC-based control.

Therefore, further research will be directed to these aspects and a different 


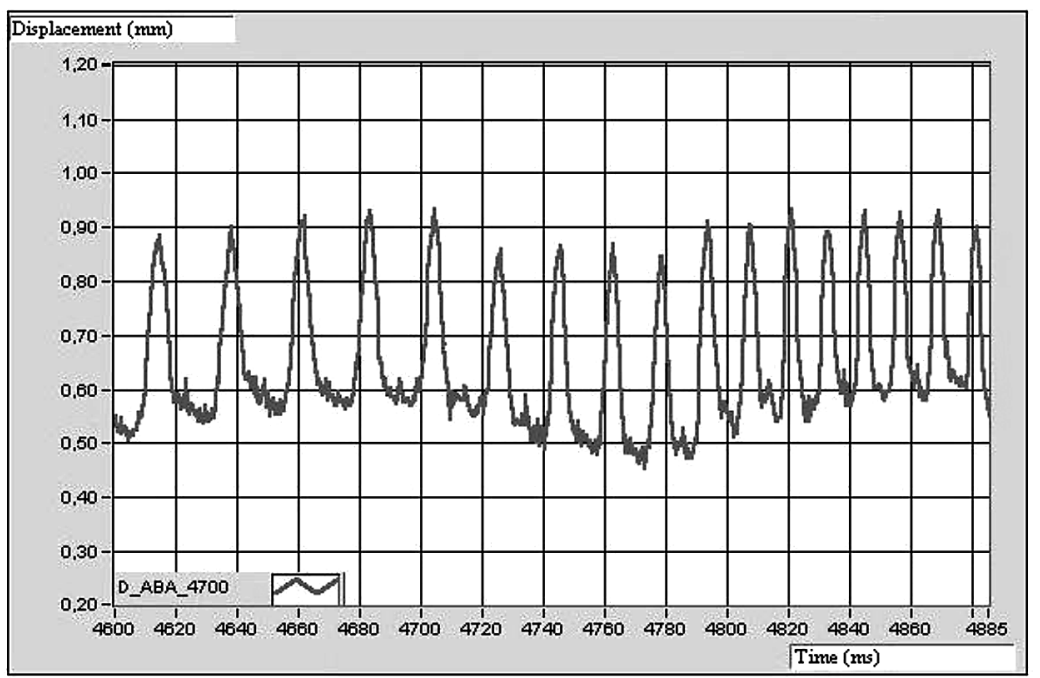

Figure 10 Displacement waveforms obtained from low-to-high speed transitions

approach will also be considered in future work, using specially designed fuzzy logic or neuro-fuzzy control schemes according to our application needs. The advantages and disadvantages of different control strategies studied will then be analysed and discussed in order to reach (and implement) an adequate self-adaptive controller, enabling the presser foot to adapt dynamically to common process conditions (like the change of number of plies that might occur during sewing).

\section{Conclusions and future research work}

To avoid the lack of fabric control, especially at high-speed sewing, a presser foot actuation set-up based on a proportional force solenoid was developed. According to the waveforms acquired and seam quality evaluation, the adopted actuation system is reliable and adequate to provide a controlled movement of the fabric plies for all tested speeds.

Using this actuation set-up and the principles stated for monitoring fabric feeding efficiency based on a new concept for seam quality assessment, named ADL, a software driver was designed to apply a constant force to the presser foot bar and PC-based open-loop and closed-loop control (PID) systems were proposed and implemented.

The open-loop control was designed considering sewing speed as the control variable, while the closed-loop control used presser foot bar maximum displacement peaks, as a direct measure of the feeding efficiency. As a first approach towards the design of an adequate presser foot closed-loop control for high-speed sewing machines, the obtained displacement waveforms showed that it is possible to control this feeding component for a wide range of speeds (up to a total variation of $2700 \mathrm{spm}$ ), firmly securing the fabric plies during the whole stitch cycle. 
All these contributions, along with needle penetration and stitch formation studies, will enable sewing machines to set up automatically, self-adjusting to the required operation settings prior to and during the sewing process. Nevertheless, some work remains to be done. Further research activities will be focused on achieving even better presser foot control performance, improving the closed-loop controller here presented, and on testing other control strategies, in order to reach the implementation of a totally self-adaptive controller for practical use in an industrial environment.

Furthermore, due to a co-operation protocol that has been established between the Sewing Research Group (including the authors and other research members of University of Minho) and a major European sewing equipment manufacturer, future work will also be focused on testing the achievements gathered in these research domains (needle penetration, stitch formation and fabrics feeding) on lockstitch sewing machines. This protocol represents the industrial recognition of all the research work undertaken at the Laboratory of Process Research, since the early days of last decade, that led to the development of the first sewability tester to improve sewing machine design and performance.

\section{Acknowledgements}

The authors are grateful to FCT (Fundação para a Ciência e a Tecnologia) for sponsoring modules of the work reported in this paper (project numbers: POSI/EEI/2078/98/2001; POSI/SRI/38944/01).

\section{References}

Carvalho, H., Ferreira, F.N., Monteiro, J. and Rocha, A.M. 1998: A sewing rig with automatic feature extraction. In Adolfsson, J. and Karlsén, J., editors, Proceedings of the 6th UK Mechatronics Forum International Conference Mechatronics '98, University of Skövde, Sweden: Pergamon, 727-32.

Carvalho, H., Rocha, A.M., Ferreira, F.N. and Monteiro, J. 2000: The development of support tools for high-speed sewing machine setting, monitoring and control. In Proceedings of the Third International Symposium on Intelligent Automation and Control - ISIAC '2000 (CD-ROM). Maui, Hawaii: TSI Press.

Carvalho, M. and Ferreira, F.N. 2000: Seam qualification and control of parameters in an overlock sewing machine. In Ferreira, F. N. and Cruz, D., editors, Proceedings of The Fiber Society Technical Meeting - Spring 2000.
University of Minho, Guimarães: University of Minho Press, 89-92.

National Instruments, 2001: LabVIEW PID control toolset user manual. Part Number 322192A-01, USA.

Rocha, A.M., Ferreira, F.N., Araújo, M., Monteiro, J., Couto, C. and Lima, M.F. 1996: Mechatronics in apparel: control, management and innovation on the sewing process. In King, T.G., Lima, M. and Parkin, R.M., editors, Proceedings of the 5th UK Mechatronics Forum International Conference - Mechatronics '96. University of Minho, Guimarães: University of Minho Press, Vol. II, 109-14.

Silva, L.F., Lima, M., Couto, C., Coelho, J., Ferreira, F.N. and Rocha, A.M. 2000a: Mechatronics approach for a controlled actuation of the presser foot mechanism on an industrial sewing machine. Acta Polytechnica 
- Journal of Advanced Engineering Design (Special Issue, no. 4), 40, 35-43.

Silva, L.F., Lima, M., Ferreira, F.N., Rocha, A.M., Carvalho, H. and Couto, C. 2000b: A new electromagnetic actuated fabric feeding system for sewing machines. In Proceedings of the 7th Mechatronics Forum International
Conference - Mechatronics'2000 (CD-ROM). Georgia Institute of Technology, Atlanta, Georgia: Pergamon.

Silva, L.F. 2002: Estudo de mecanismos alternativos de controlo do sistema de alimentação de máquinas de costura industriais. PhD Thesis, School of Engineering, University of Minho. 